Abstracta Iranica

Revue bibliographique pour le domaine irano-aryen

Volume 34-35-36 | 2017

Comptes rendus des publications de 2011-2013

\title{
N. Akhavan. Electronic Iran: the cultural politics of an online evolution
}

\section{Laetitia Nanquette}

\section{(2) OpenEdition}

1 Journals

Édition électronique

URL : http://journals.openedition.org/abstractairanica/41373

DOI : 10.4000/abstractairanica.41373

ISSN : 1961-960X

\section{Éditeur :}

CNRS (UMR 7528 Mondes iraniens et indiens), Éditions de l'IFRI

\section{Référence électronique}

Laetitia Nanquette, "N. Akhavan. Electronic Iran: the cultural politics of an online evolution », Abstracta Iranica [En ligne], Volume 34-35-36 | 2017, document 2, mis en ligne le 15 juillet 2016, consulté le 29 septembre 2020. URL : http://journals.openedition.org/abstractairanica/41373 ; DOI : https://doi.org/ $10.4000 /$ abstractairanica.41373

Ce document a été généré automatiquement le 29 septembre 2020.

Tous droits réservés 


\title{
N. Akhavan. Electronic Iran: the cultural politics of an online evolution
}

\author{
Laetitia Nanquette
}

\section{RÉFÉRENCE}

N. Akhavan. Electronic Iran: the cultural politics of an online evolution. New Brunswick, New Jersey, Rutgers University Press, 2013, 149 p.

1 Cet ouvrage analyse d'un point de vue ethnographique le rôle politique joué par l'Internet en Iran. Akhavan étudie les années 1998-2012 et montre la diversité des positions qu'on peut trouver sur l'Internet iranien en ce qui concerne les questions de politique et de société ou la définition de l'identité iranienne.

2 Cet ouvrage apparaît quelques années après d'autres textes sur la blogosphère, ou « weblogistan ", qui faisaient des blogs un lieu peuplé de jeunes gens luttant contre l'Etat.

3 Akhavan conteste en partie ces textes et offre une vision plus complète, montrant combien la blogosphère et l'Internet sont plus variés et plus complexes que ne le décrivait ce discours. Elle s'attache notamment à étudier les sites qui ne sont pas d'opposition et à montrer combien l'Etat s'est investi dans la création de sites promouvant son discours.

4 Dans son premier chapitre, elle s'intéresse à la mobilisation autour de la dénomination " golfe Persique », plutôt que « Golfe » ou «Golfe Arabique », qui a été un des moments clés pour un dialogue en ligne sur l'identité iranienne, commencé par des sites de la diaspora, et continué par la République islamique. Akhavan montre les contradictions de l'Etat dans son rôle vis-vis de l'Internet, qu'il a développé, qu'il s'attache à surveiller et censurer, mais qu'il utilise aussi pour promouvoir son idéologie. D'autres chapitres s'intéressent aux medias sociaux ou à l'usage de l'Internet dans le discours de la “défense sacrée".

5 Cet ouvrage fondé sur une étude extensive de sites et blogs iraniens (en persan et en anglais pour inclure la diaspora), est bienvenu pour montrer combien l'Internet iranien 
est dynamique et varié. Il contribue à une réflexion nuancée sur les potentialités mais aussi les dangers de la toile.

\section{AUTEURS}

\section{LAETITIA NANQUETTE}

University of New South Wales, Sydney 